\title{
Definition of the inspection criteria for personal protective equipment (for work at heights) on example of full body harnesses
}

\author{
Vasily Vasilenko, Dmitry Korolchenko* and Pham Nam Thanh \\ Moscow State University of Civil Engineering, Yaroslavskoe shosse, 26, Moscow, 129337, Russia
}

\begin{abstract}
Works at heights can be unit in the separate sector of works which requires increased risk control and labor protection measures. According to the accident statistics this sector is one of the most hazardous and problematic. The problem of application of full body harnesses to protect workers against the risks of falling from heights is considered in this article. Herewith the importance of operational aspects revealed after purchase of applicable certified personal protection equipment for work at heights (further PPE) is particularly noted. Features of technical/detailed inspections of PPE and training of experts in this field in Russian Federation are presented. The analytical part of the article contains basic information about main damages and standard defects of full body harnesses which could become the basis of a normative document (further ND) for PPE inspection. ND in turn would help to form the general inspection criteria for PPE of various types, and would become normative «foundation» to train specialists. It is shown that GOST R EN 365 need to be reformed in accordance with priorities of domestic market.
\end{abstract}

\section{Introduction}

Today all work at heights in Russian Federation connected with various construction works, reconstruction of buildings and objects and other operational tasks and can be unit in the separate sector of works which requires increased risk control and labor protection measures. Thus in accordance with official statistic sources fall from heights in Russian Federation is one of the leading causes of death and injury in the workplace [1-3]. This type of injury accounts $30 \%$ of all heavy and «lethal» statistics and, if we consider fatal cases, it can account more than 35\% [4-11]. One of the ways to solve such problem is application of personal protective equipment against falls from a height in order to prevent any accidents and possible consequences. Some types of PPE are also intended for rescue and evacuation operations in case of emergency situations at a height [12-18]. Modern PPE, presented on the security market, cover a full range of equipment ensuring safety of work at heights: from the rope access systems to simple ensuring the safety of the worker staying at the

\footnotetext{
"Corresponding author: ikbs@mgsu.ru
} 
point of non-fenced place at a height. Full body harnesses are widely presented at the security market of our country (fig.1).

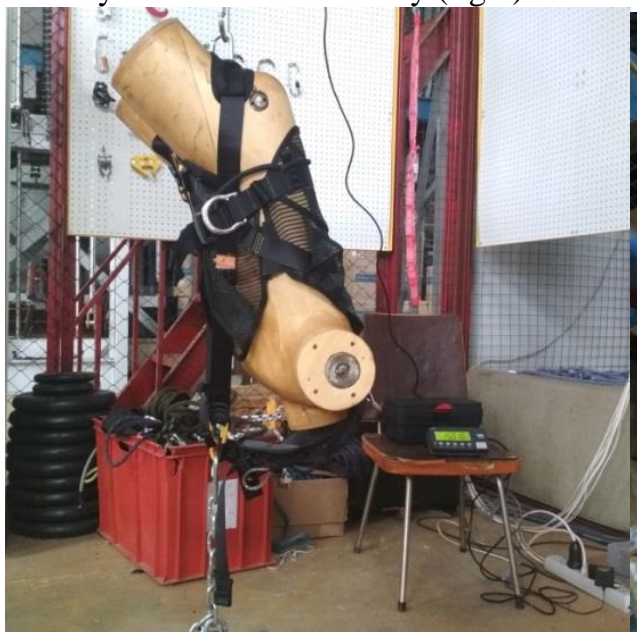

a)

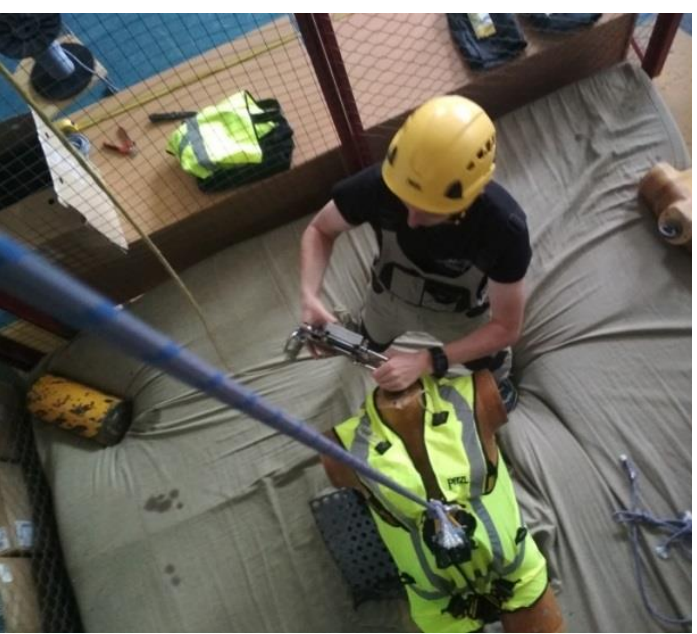

b)

Fig. 1. Certification tests of full body harnesses in the test laboratory of the Institute of complex safety in construction: a) Static tests, b) Dynamic tests.

Certification procedure for PPE, regulations on labor protection and procedure for the employer and for the worker during organization of work at heights are regulated by such standard documents as TR CU 019/2011 «On the safety of personal protective equipment» and Rules of labor protection during work at height, the order No. 155n [15]. One of the important aspects of «life activity» and safety of PPE for today is the question of its usage; regulations stated above do not consider such matters. One of the main problems of usage and service of PPE in turn is the inspection carried out by the competent person. Regular inspection allows to keep PPE in operating and safe conditions and to dispose timely if it has any defects. The right of inspection, in accordance with Rules [15], is assigned to workers of the third safety group for work at heights, but we have no certain inspection algorithms, standard examples and normative documents for workers of such group. Now the procedure of training of the competent person includes only programs and techniques developed by manufacturers and each manufacturer issues the certificate to carry out inspection of its PPE. Thus the certificate given by educational institution does not allow carrying out fully inspection of products without certificate of the manufacturer.

The aim of this work is to increase the safety of works at a height. Identification of deterioration criteria of full body harnesses could form the basis of normative document which could help to make independent inspection of PPE without a binding to the manufacturer.

\section{Analytical part}

Full body harness is the one of components of the safety system for work at heights and it should be used every time when the risk of falling from a height is appeared. We have the following types of full body harnesses: safety, holding, adopted for a sitting position, rescue and combined. Most often it consists of the textile webbing sewed in accordance with certain configuration and fitted with buckle attachments allowing adjusting the length of webbing, position of attachment points of connecting and shock absorbing subsystems.

During exploitation full body harnesses are exposed to various deterioration factors such simple as time factor when the textile loose the strength characteristics and also 
chemical and thermal effects. The life cycle of full body harnesses begins from the production stage, when all equipment passes through the quality control system and sent to the warehouse with appropriate marking. After purchase full body harnesses become the property of a private person or a legal entity and put into operation with primary inspection, filling appropriate forms and fixing the name of responsible worker. The life cycle of the product can vary, but even it was not use for a long time it should be thoroughly inspected at least once a year to reveal any defects and to confirm further exploitation. The "life time" of product finishes in case of several options: natural wear, expiration of the standard operation date, defects related to dynamic or static impact loads and etc.. In all cases the product is exposed to elimination and subsequent utilization.

Possible critical damage of full body harnesses:

1) Full body harnesses stop the falling (Fig.2)

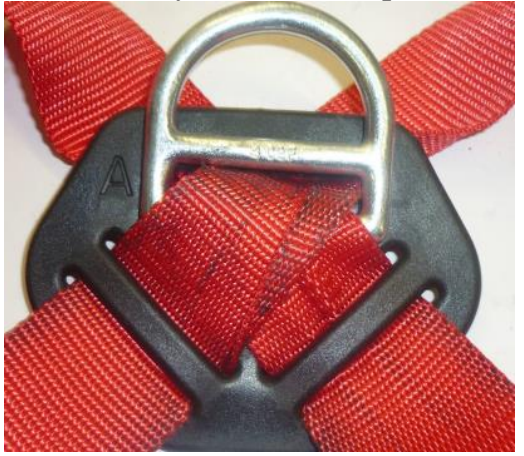

a)

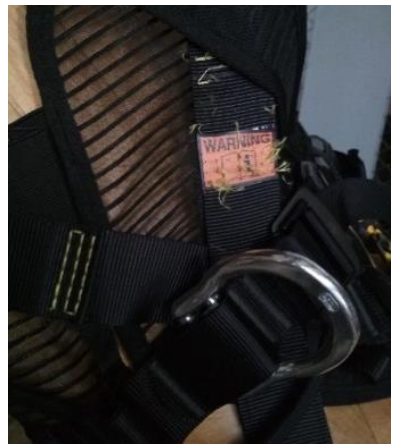

b)

Fig. 2. Condition of full body harnesses after the effect of the dynamic load in case of stopping the fall: a) marks on the webbing b) thrust indicator in the point of $400 \mathrm{~kg} / \mathrm{s}$.

According to these examples full body harnesses worked for its direct appointment: stopped the falling and kept the life and the health of a worker. After such extreme loads reuse the full body harnesses does not guarantee the safety of its further application. It should be utilized. The worker is obliged to report about any fact of the occurred incident to his chief. But if this requirement was not met then the thrust indicator could significantly simplify the process of rejection.

2) Damaged power seams stitched with filament of other color (Fig. 3).

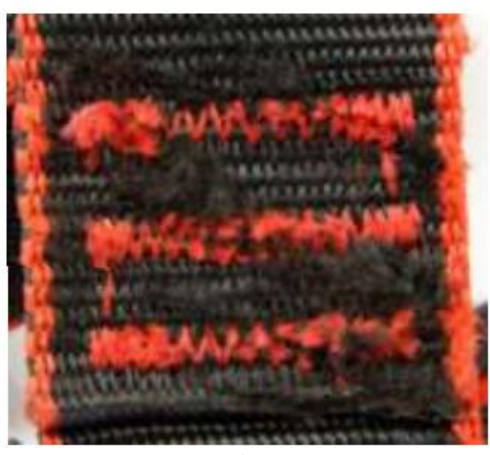

a)

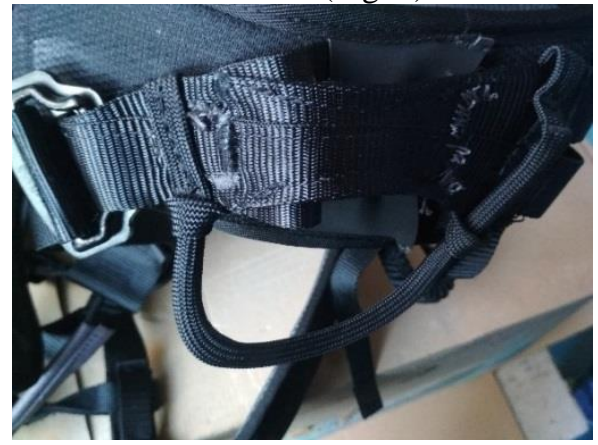

b)

Fig. 3. Damaged power seams stitched with filament of other color. 
The most part of loads to full body harnesses is transferred to seams which connect the tapes in webbing, which surely have to be in a good repair. Presence of mechanical or chemical damages on a power belt and on seams creates the dangerous situation. Such products should be utilizied.

3) Deformation of connectors and buckles (Fig.4)

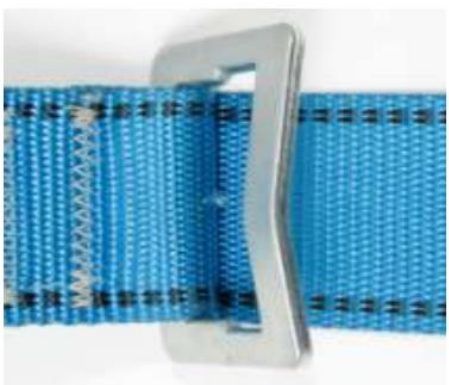

a)

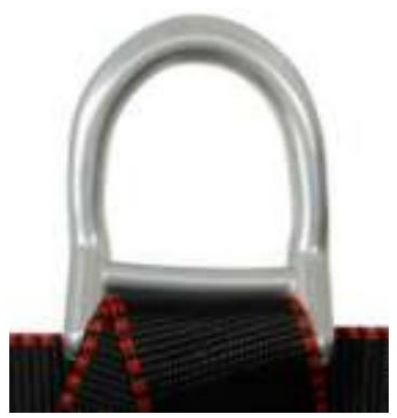

b)

Fig. 4. Deformation of the metal anchor elements: a) deformed quick-connect buckle; b) deformed anchor point.

Deformation of the metal elements is already shown the excessive loads on the product. The deformed buckle could not fix the tape correctly. As a matter of fact, deformations in any metal part cause the tension and the reduction of strength characteristics.

4) Corrosion of load-bearing metal elements (Fig. 5).

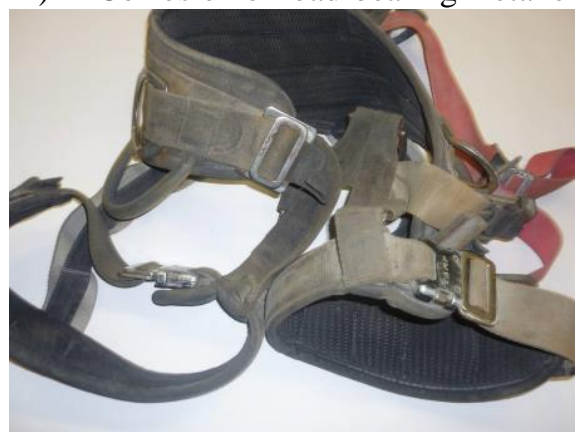

a)

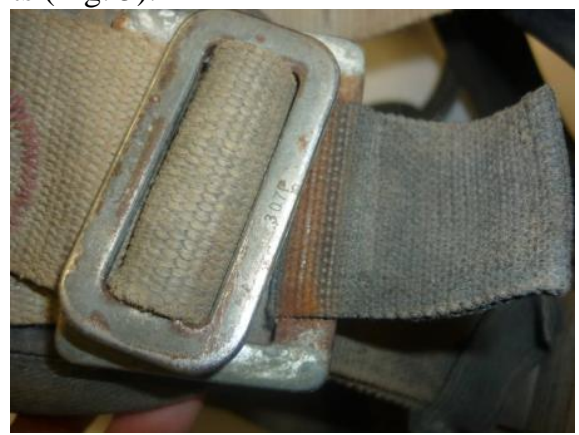

b)

Fig. 5. Corrosion of load-bearing metal elements: a) complete wear due to intensive exploitation, b) deep corrosion of buckles.

Corrosion adversely affects metal components and their strength characteristics. At the initial stage of corrosion (some manufacturers allow the stage up to 10\%) the product can be work out and cleaning, but if the corrosion will reach larger percentage the full body harnesses will need to be amortized.

5) Chemical and thermal damages of power belts (Fig. 6).

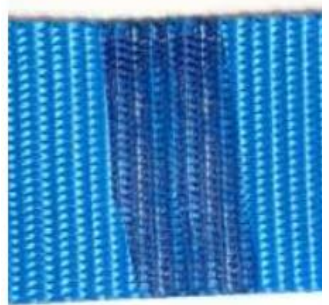

a)

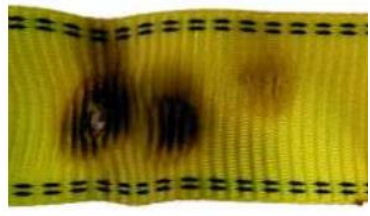

b)

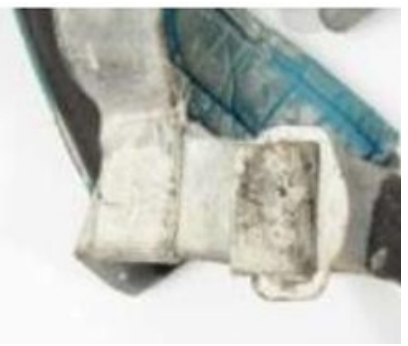

c)

Fig. 6. Chemical and thermal damage of power belts: a) special color marks, b) thermal damage of a belt; c) chemical damage of a belt. 
Chemical and thermal damages of power belts which affect the bearing capacity of a product. For example, the acid getting on textiles from the automobile accumulator can lower the strength characteristics of a product from $15 \mathrm{kN}$ to $2 \mathrm{kN}$; that is the critically low value. The contact of a product with various paints, solvents, mixes, markers, oils, fuel and etc. belongs to chemical damages.

6) Defects of integrated shock absorber (Fig.7).

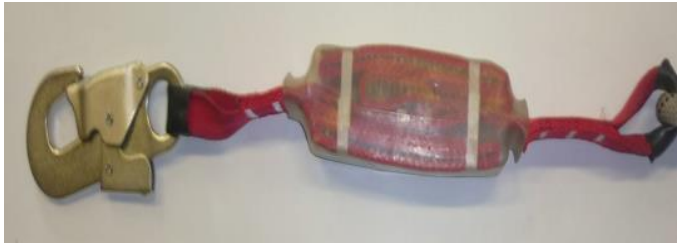

a)

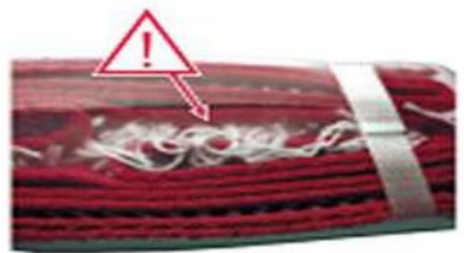

b)

Fig. 7. Defects in integrated shock absorber. Partial disclosure of the shock absorber.

In some cases the full body harnesses have the integrated shock absorber as a component of safety system in order to increase the dynamic loadings in case of falling down to safely $6 \mathrm{kN}$. Traces of defects of the shock absorber can reveal its unsuitability for further operation, as well as the fact when the shock absorber has already used to stop the fall. Therefore the force applying to the human body in case of repeated fall will exceed the established safe limit of $6 \mathrm{kN}$.

7) The enhanced wear rate and expiration of the product (Fig.8).

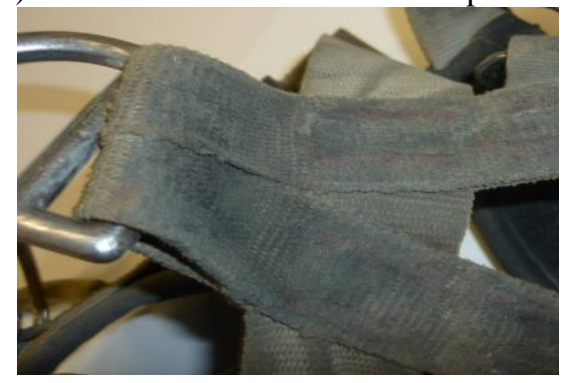

a)

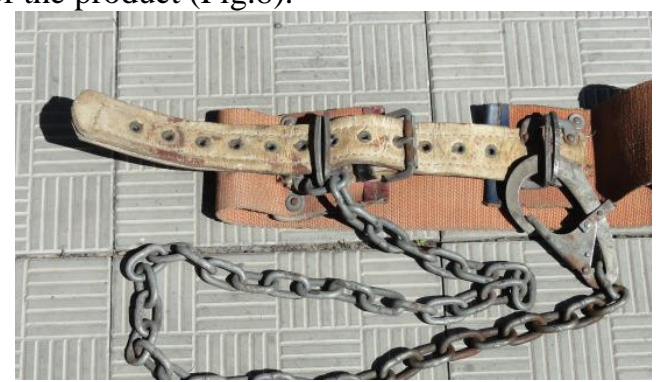

b)

Fig.8. The enhanced wear rate and expiration date of the product.

Date of natural wear of a product can occur due to the intensive exploitation before the last lifetime date when the product should be rejected. Also the product can become non actual both morally and physically. The «moral obsolescence» of a product is firstly connected with changing in normative regulation acts and also with work principles. Each product physically has the expiration date, and if you exceed it the product become dangerous.

For the qualified and easily understood principle of the inspection procedure it is necessary to create the algorithm which would provide rejection of PPE at early stages of elementary or critical damages (Fig. 9). 


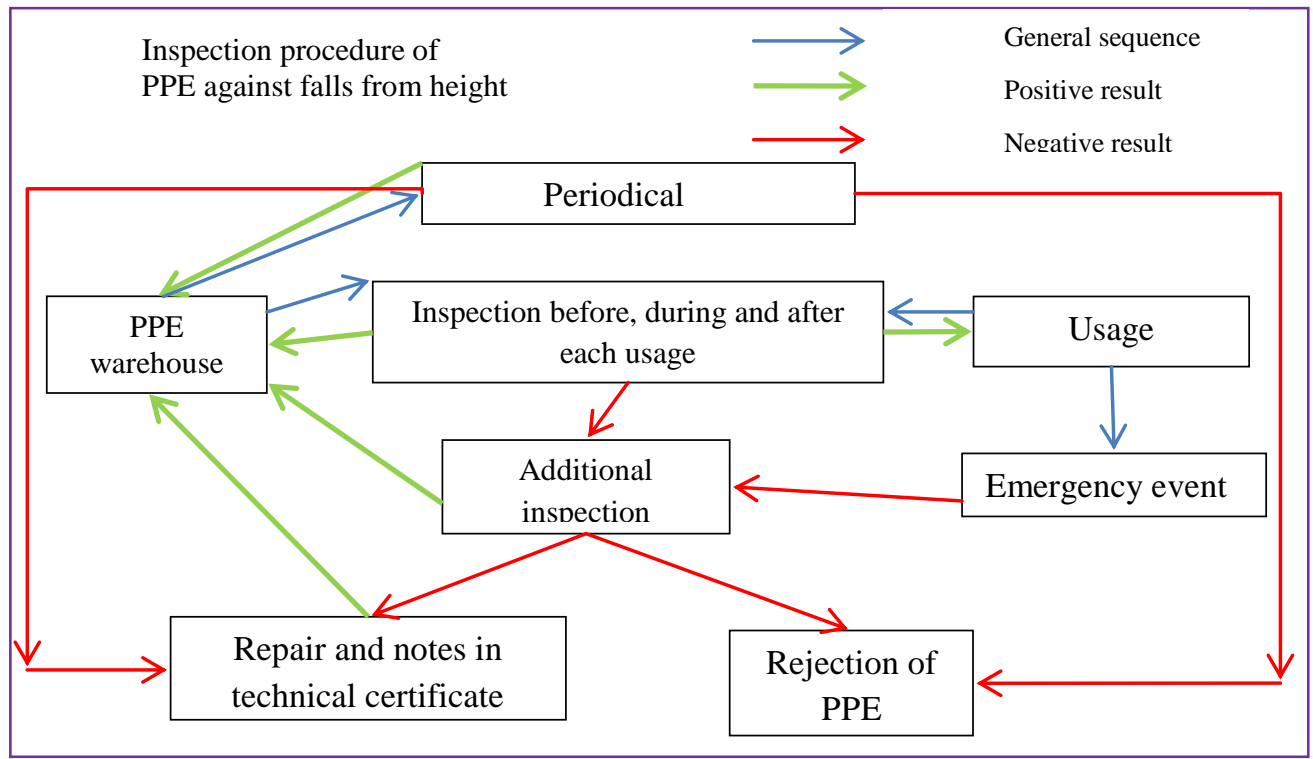

Fig. 9. The inspection procedure of PPE on the example of the Italian company (C.A.M.P).

Inspections could be subdivided into several different types:

- Inspection before each usage of PPE. Superficial inspection of all the system components conducted by competent worker. The right to carry out such inspections is affirmed by Order of the Ministry of Labor No. 155n with amendments №363n [19];

- Inspection of products in case of emergency situations. Falling of user, falling of a product, sharp sign-variable loadings and change of weather conditions;

- Detailed inspection of PPE. At least once in a year it is necessary to make detailed inspection of PPE to reveal the possible damages and defects.

Detailed inspection begins with checking the product for compliance with the existing data card. And the first step is the identification of PPE by individual product number and registered number in database. If the product cannot be identified it should be write-off because we have no guarantee of its safety usage. The next step is to clean the product from anything that may prevent the inspection. Further we should verify all the elements of full body harnesses: anchorage, body support and connections. Check of integrity and condition of the «breakdown indicator» should be also done in case of its presence in construction. Check for any signs of repair or changes in design which are not provided by the manufacturer and verification the correct assembly of the product should also be done. One of the verification mechanisms is a comparison of the product with another similar one. In such case we can identify the absence or presence of changes in fittings and ropes of the PPE. After that we should made a detailed inspection of mechanical, chemical, thermal and other damages by means of visual and tactile methods. If the detailed inspection of the product show that it suitable for operation, then we should fill the form indicated the inspection date, results of inspection and information about responsible person (Table 1.).

Table 1. Example of filled form of «Vento» company

\begin{tabular}{|c|l|l|}
\hline \multicolumn{2}{|c|}{ Equipment document } & Full body harnesses \\
\hline Equipment: & Trade name: & $\begin{array}{c}\text { Identification number, } \\
\text { individual article number: }\end{array}$ \\
\hline $\begin{array}{c}\text { Model } \\
\text { type/identification: }\end{array}$ & Address: & Phone, e-mail, website: \\
\hline Manufacturer: &
\end{tabular}




\begin{tabular}{|l|l|l|l|l|}
\hline $\begin{array}{c}\text { Production } \\
\text { lifetime date: }\end{array}$ & date/ & Date of purchase: \\
\hline \multicolumn{9}{|l|}{ Application date: } \\
\hline Schedule of periodical inspections and repairs \\
\hline Date: & $\begin{array}{l}\text { Reason of } \\
\text { checkup } \\
\text { (periodical } \\
\text { inspection } \\
\text { repair). }\end{array} \quad$ or & $\begin{array}{l}\text { Revealed } \\
\text { defects, type } \\
\text { of repair, } \\
\text { additional } \\
\text { information. }\end{array}$ & $\begin{array}{l}\text { Family } \\
\text { name and } \\
\text { signature of } \\
\text { the competent } \\
\text { person. }\end{array}$ & $\begin{array}{l}\text { Next date of } \\
\text { periodical } \\
\text { inspection. }\end{array}$ \\
\hline & & & & \\
\hline
\end{tabular}

Unification of methods and norms of the detailed inspection by means of introduction the regulatory legal acts containing uniform instructions and requirements that will allow increasing the safety level of work at heights. Such inspections often aren't carried out, and we should enhance the control to increase the safety level tree times. Sometimes methods of inspection and identification of defects have indirect character and are based on experience and guesses of the responsible persons. Introduction of such definition as "indicator" into standardization and technical regulations for PPE would help to identify explicitly the suitability of a product for further operation But now only few of manufacturers make the built in indicators.

\section{Conclusion}

On the basis of the above stated it is necessary to create the normative document for usage of PPE which would contain the following:

- the common criterion of wear for all types of PPE according to existing state standard specifications;

- examples and images of deterioration of various PPE;

- decision algorithms for the competent person to further exploitation or elimination of PPE;

- requirements to registration documentation.

This regulatory base will allow training experts to make complete inspection of all types of PPE at their workplaces. In case of difficult nonstandard situation it is necessary to define the interaction scheme for the competent person and the representative of PPE manufacturer.

For today only large trade marks presented on PPE market have registration documentation for detailed inspection but great number of manufacturers sail the equipment without such documentation.

Also the item 92 and the item 95 of Regulations [15] raising the question of periodic inspection specify that it is necessary to be guided by «documentation of PPE manufacturer» and «instructions in their operation documentation». It is rather difficult to enter full information about inspection in operation documentation because of its large volume as the manufacturer indicates in documentation only short description on this issue. For example: «PPE against falls from a height should be immediately remove from service if :

- it did not meet safety requirements during preoperational or periodic inspection;

- it already was used to prevent falling;

- it was used for other purposes;

- it have not appropriate marking of manufacturer;

- we have no information about previous operation of this PPE;

- the service live has expired; 
- the storage life has expired;

- it was repaired or modified in non-authorized center;

- we have any suspicions about integrity (completeness, compatibility) of PPE».

In spite of the fact that item 4.1 of GOST R EN 365 indicates that the manufacturer should create instructions for periodic inspection, and items 4.4, 4.7 include requirements to such inspections, this standard have not detailed typical examples of product defects.

Thus it is necessary to reform the GOST R EN 365 in accordance with priorities of domestic market and to create the ND for periodic and detailed inspections of PPE.

This work was financially supported by Ministry of Science and Higher Education of the Russian Federation (\#NSh-3492.2018.8).

All tests were carried out using research equipment of The Head Regional Shared Research Facilities of the Moscow State University of Civil Engineering.

\section{References}

1. Report of the Ministry of Labour and Social Protection of the Russian Federation (from 09.07.2013) «On implementation of state policy in the field of conditions and labor protection in the Russian Federation in 2012»;

2. Report of the Ministry of Labour and Social Protection of the Russian Federation (from 21.07.2014) «On implementation of state policy in the field of conditions and labor protection in the Russian Federation in 2013»;

3. Report of the Ministry of Labour and Social Protection of the Russian Federation (from 03.11.2015) «On implementation of state policy in the field of conditions and labor protection in the Russian Federation in 2014»;

4. Rashitov G.S., Abdyukova G.M. «The analysis of industrial injuries at construction objects», Collection of scientific papers, All-Russian scientific and practical conference with international participation (Ufa, October 21-23, 2015), In 3 volumes, 2015, Volume 2., 286 pages.

5. Savelyeva E.A. How to create an effective safety system for working at heights? Choosing optimal solution for any work space, Scientific and technical journal «Ugol», 2016. No. 11, pp. 45-46.

6. Senchenko V. A., Kaverzneva T.T. Organizational safety measures when working at height on small enterprises in construction, «Bezopasnost i okhrana truda» journal, 2015. No. 3 (64), pp. 71-76.

7. Senchenko V. A. Safety measures when working on antenna-mast structures, «Bezopasnost i okhrana Truda» journal, 2016, No. 3(68), pp. 67-69.

8. Pushenko S.L., Staseva E. V. The analysis and prevention of operational injuries at construction of high-rise buildings and works at heigh, Bulletin of theVolgograd State University of Architecture and Civil Engineering, Construction and architecture section, 2016, Issue 44(63), Part 2, pp. 157 - 165.

9. Ovcharenko. M.S. The analysis of industrial injuries in construction branch of the Russian Federation, Collection of scientific papers of the 4th International youth scientific conference, in 4 volumes, "Generation of the future: View of young scientists - 2015», November 19-20, 2015, Vol. 3, pp. 259-262.

10. Evan A. Nadhim, Carol Hon, Bo Xia, Ian Stewart, Dongping Fang. Falls from Height in the Construction Industry: A Critical Review of the Scientific Literature. // Int. J. Environ. Res. Public Health 2016, 13, 638.

11. B. Hoła. Methodology of hazards identification in construction work course. // Journal of Civil Engineering and Management, 2010, 16(4): 577-585.

12. Vedernikov A.N., Kuznetsova E.P. Collective fire protection equipment in high-rise 
buildings. Bulletin of the Perm national research polytechnic university. Applied ecology. Urbanistics, 2011, No. 3, pp. 30-37;

13. Todoseychuk S.P., Onishchenko Yu.A., Archipenko A.A. Technology and the Results of Field Testing of Rescuing People From a Height, «Technologies of civil safety», 2014. Vol. 11, No. 1 (39), pp. 42-45;

14. Korolchenko A.Ya., Afonina O.I. Protection equipment for rescue people from height in case of fire. Fire safety in construction, 2010, No. 5, pp. 62-71;

15. Korolchenko, D. , Pizhurin, A., 2017. Simulating operational control of production in lumber house building businesses S.Jemiolo et al.,eds. MATEC Web of Conferences, 117, p.00084. DOI: 10.1051/matecconf/201711700084.

16. Dmitry Korolchenko, Vasily Vasilenko and Georgy Lelikov, Problems of the dynamic test method for individual protection equipment (shock absorbers) // MATEC Web of Conferences. Volume 193, 2018

17. Nam Thanh Pham, Vasiliy Vasilenko and Dmitriy Korolchenko, Test and Certification Procedures of Pulleys as a Part of Personal Fall Arrest System // IOP Conference Series: Materials Science and Engineering, Volume 365, 2018

18. N T Pham, G Lelikov and D Korolchenko, Improvement of The Safety Systems for Working at Heights on Transmission Towers // IOP Conference Series: Materials Science and Engineering, Volume 365, 2018

19. The rules of labor protection when working at height approved by order of the Ministry of Labor of Russian Federation from 28.03.2014, No. 155n. 